\title{
Field Characterization of Partial Resistance to Gray Leaf Spot in Elite Maize Germplasm
}

\author{
James O. Nyanapah, ${ }^{1, \dagger}$ Patrick O. Ayiecho, ${ }^{1}$ Julius O. Nyabundi, ${ }^{1}$ Washington Otieno, ${ }^{2}$ and Peter S. Ojiambo ${ }^{3, \dagger}$ \\ ${ }^{1}$ Department of Applied Plant Sciences, School of Agriculture and Food Security, Maseno University, Maseno, Kenya \\ ${ }^{2}$ CABI Africa, Canary Bird, 673 Limuru Road, Muthaiga, Nairobi, Kenya \\ ${ }^{3}$ Center for Integrated Fungal Research, Department of Entomology and Plant Pathology, North Carolina State University, Raleigh, NC \\ 27695, U.S.A. \\ Accepted for publication 20 May 2020.
}

\begin{abstract}
Forty-eight inbred lines of maize with varying levels of resistance to gray leaf spot (GLS) were artificially inoculated with Cercospora zeina and evaluated to characterize partial disease resistance in maize under field conditions from 2012 to 2014 across 12 environments in western Kenya. Eight measures of disease epidemic - that is, final percent diseased leaf area (FPDLA), standardized area under the disease progress curve (SAUDPC), weighted mean absolute rate of disease increase $(\rho)$, disease severity scale (CDSG), percent diseased leaf area at the inflection

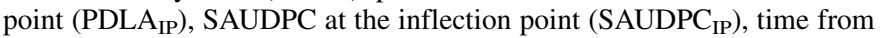
inoculation to transition of disease progress from the increasing to the decreasing phase of epidemic increase $\left(\mathrm{T}_{\mathrm{IP}}\right)$, and latent period $(\mathrm{LP})$ -

with SAUDPC $\left(R^{2}=89.4 \%\right)$. Inbred lines were also most consistently ranked for disease resistance based on SAUDPC. Although SAUDPC was deemed the most useful variable for quantifying partial resistance in the test genotypes, the proportion of the variation in SAUDPC in each plot was most strongly $\left(R^{2}=93.9 \%\right)$ explained by disease ratings taken between the VT and R4 stages of plant development. Individual disease ratings at the $\mathrm{R} 4$ stage of plant development were nearly as effective as SAUDPC in discerning the differential reaction of test genotypes. Thus, GLS rankings of inbred lines based on disease ratings at these plant developmental stages should be useful in prebreeding nurseries and preliminary evaluation trials involving large germplasm populations.
\end{abstract} were examined. Inbred lines significantly $(P<0.05)$ affected all measures of disease epidemic except $\rho$. However, the proportion of the variation attributed to the analysis of variance model was most strongly associated
Keywords: Cercospora zeina, disease resistance components, ecology and epidemiology, epidemic rate, quantitative resistance, Zea mays
Gray leaf spot (GLS) caused by the fungal sibling species Cercospora zeae-maydis and C. zeina is one of the most important foliar diseases of maize under conservation tillage in temperate regions and most maize-growing areas in the tropics (Ward et al. 1999). The two causal agents of GLS are genetically and phenotypically distinct, with $C$. zeae-maydis being the predominant species in the United States, while $C$. zeina is the species that is present in Africa (Crous et al. 2006; Goodwin et al. 2001). Indeed, studies conducted in Africa have confirmed C. zeina as the causal agent of GLS on maize in southern Africa (Meisel et al. 2009) and Kenya (Kinyua et al. 2010). The disease is most common on mature leaves, where it induces elongated chlorotic or necrotic spots that are delimited by leaf veins. Prolonged exposure of infected plants to weather conditions that are conducive for disease development can result in severe blighting and stalk deterioration and, subsequently, lodging and even premature death of affected plants (Stromberg 1986). Yield losses ranging from 70 to $100 \%$ have been reported (Danson et al. 2008; Sibiya et al. 2012), especially if susceptible cultivars are infected at the most vulnerable stage of plant development (Lipps 1995; Ward et al. 1999). In sub-Saharan Africa, GLS continues to be an important foliar disease of maize and has been reported to account for more than $25 \%$ of yield loss within the region (Sibiya et al. 2012).

${ }^{\dagger}$ Corresponding authors: J. O. Nyanapah; jonyanap@yahoo.co.uk; and P. S. Ojiambo; pojiamb@ncsu.edu

Funding: This work was supported, in part, by funds from the German Academic Exchange Service (DAAD). P. S. Ojiambo was supported by Hatch Funds from North Carolina Agricultural Experiment Station for Project NC02693.

The author(s) declare no conflict of interest.

C 2020 The American Phytopathological Society
Host genetic resistance is considered the most cost-effective and environmentally sound strategy for sustainable management of GLS (Kim et al. 2011; Kuki et al. 2018). Both qualitative and quantitative resistance to GLS have been identified (Ayers et al. 1985; Balestre et al. 2012; Coates and White 1998; Gevers and Lake 1994; Menkir and Ayodele 2005). Qualitative resistance to GLS is conditioned by a single dominant gene and is characterized by formation of chlorotic lesions (Freppon et al. 1996). However, it has not been widely exploited primarily because of its anticipated shortterm effectiveness due to the potential emergence of new races of the pathogen in natural populations (Freppon et al. 1996). In contrast, quantitative resistance, also known as partial, horizontal, or rate-reducing resistance, is considered highly effective in the management of GLS (Gordon et al. 2006; Menkir and Ayodele 2005). Quantitative resistance is conditioned by multiple loci with predominant additive gene action (Benson et al. 2015; Berger et al. 2014) and has previously been viewed as a form of incomplete resistance in which sporulation is reduced even though host plants are susceptible to infection (Parlevliet 1979). Thus, this type of resistance has an overall effect of slowing down epidemic progress by limiting the buildup of secondary inoculum through various "disease resistance components" during the infection cycle of the pathogen. These resistance components include latent period, infection efficiency, lesion size, lesion expansion rate, number of spores per lesion, and sporulation period (Parlevliet 1979; Rufty and Main 1989; Seebold et al. 2001). In the GLS-maize pathosystem, partial resistance has previously been associated with prolonged incubation period, an extended latent period, a slower apparent rate of disease increase, reduced infection rates and efficiency, and reduced sporulation (Gordon et al. 2006; Ringer and Grybauskas 1995). Although studies on components of partial resistance to GLS have primarily been conducted under greenhouse conditions (Asea et al. 2005; Lyimo et al. 2013; Paul and Munkvold 2005), few (Asea 
2001; Bair and Ayers 1986; Benson et al. 2015) have correlated results from greenhouse studies with those obtained under field conditions. Furthermore, the association of disease resistance components with partial resistance to GLS under field conditions has not been well characterized.

Previous attempts to characterize partial resistance to GLS in juvenile and adult maize plants have generated conflicting results. For example, Saghai Maroof et al. (1993) detected significant correlations between GLS severity levels across different growth stages of maize. However, reduced correlations between early and late GLS ratings with increased interludes between ratings during crop development were reported by Bubeck et al. (1993). In addition, Gordon et al. (2006) found that genotypic effects associated with sporulation from GLS lesions were not clearly demarcated between resistant and susceptible maize genotypes. The latter led to the speculation that necrotic leaf tissues could not exhibit differences in sporulation when infected by different genotypes of $C$. zeae-maydis or $C$. zeina within the pathogen population. Thus, the overall goal of this study was to assess the variability and consistency of disease resistance components of GLS at different growth stages of maize under field conditions. The specific objectives of this study were to (i) establish the relative contribution of various measures of disease and resistance components to the overall partial resistance to GLS, (ii) identify a disease assessment or resistance component variable useful for quantifying partial resistance to GLS in maize, and (iii) determine disease severity ratings during crop growth that are useful for rapid and efficient GLS resistance screening in large maize-breeding programs.

\section{MATERIALS AND METHODS}

Test germplasm. Forty-eight elite maize inbred lines (Table 1) obtained from the International Maize and Wheat Improvement Center (CIMMYT) in Mexico were multiplied through controlled hand pollination according to a 16-step mating protocol (Schnable Lab 2014). These inbred lines represented a genetically diverse sample of elite maize germplasm of varying heterotic groups and were presumed homozygous (Vasal et al. 1999). Some of the inbred lines also have significant value-addition traits such as low $\mathrm{N}$-use efficiency, high-quality protein content, and resilience to acidic soils, with several serving as parents of commercial hybrids (Diallo et al. 2001; Vasal et al. 1993). Furthermore, many of these inbred lines have good combining ability and are specifically adapted to abiotic and biotic stresses such as GLS in tropical and subtropical regions (Makumbi et al. 2011). Preliminary evaluation of these lines was undertaken at a breeding nursery in Kehancha, western Kenya, to identify and exclude inbreds with putative qualitative resistance to GLS, which can confound the expression of partial resistance (Geiger and Heun 1989). This effort was part of a broader study to investigate inheritance of quantitative resistance to GLS in maize.

Field layout and experimental design. Inbred lines were evaluated from 2012 to 2014 in six sets (eight lines per set) in 12 trial environments in Kenya, where each environment represented a single location-year-season combination (Table 2). In this study, a set represented a heterotic group of genotypes that displayed a similar combining ability and response when crossed with genotypes from other genetically distinct groups. In a given year, field experiments were conducted during the either long rain season (March to July), short rain reason (August to November), or both. Inbred lines were evaluated in a randomized complete block design with three replications. The layout of the plot at each trial site was generated using PROC PLAN of SAS (SAS Institute Inc. 2011). Each plot of a single inbred line comprised three 3-m rows spaced $0.75 \mathrm{~m}$ apart and with $0.25 \mathrm{~m}$ between hills in a row, leading to a total of 36 plants/plot. Within rows, seed of inbred lines were planted by placing two kernels in a hill at a depth of $3 \mathrm{~cm}$ and covering the kernels with a 2- to 3-cm layer of top soil. Each hill received $5 \mathrm{~g}$ of diammonium phosphate fertilizer (DAP-46) at planting. At the V1 plant development stage (Ritchie et al. 1993), hills were thinned to leave only one plant per hill. To minimize interplot interference, adjacent plots were separated by two rows of sorghum (variety Seredo). A 1-m-wide alley between plots was left fallow to facilitate movement during data collection. To reduce the risk of early natural infection of plants before they were artificially inoculated, seed were sown in plots at the start of the growing season in fields that were at least $75 \mathrm{~m}$ away from the nearest sites where maize had been grown in the season immediately preceding each trial. All standard agronomic and cultural practices recommended for maize production in Kenya were followed at all trial locations. Weather conditions during the growing season at each location were recorded using Onset Hobo portable data loggers (Onset Computer Corp., Pocassett, MA, U.S.A.).

Inoculum preparation and inoculation. A wild-type mixed population of $C$. zeina was used as inoculum to avoid any host-pathogen interaction that could confound genotype-environment interactions (Geiger and Heun 1989). To prepare the inoculum, leaf samples were collected in the season immediately preceding each field trial by gathering heavily infected leaves of heterogeneous maize cultivars grown across three counties in Nyanza Province in Kenya. Senescing leaves of maize plants with a GLS severity score of 5 based on the CIMMYT (1985) disease severity scale were air dried in the shade, placed in dry paper bags, and stored for 4 to 6 weeks at room temperature in the dark. Conidial suspensions were prepared from the stored leaves using a procedure similar to that of Carson (1995). Briefly, infected leaf samples were removed from storage, placed in sealed plastic containers with moist paper towels, and incubated for $72 \mathrm{~h}$ at room temperature under normal daylight to induce conidiation. These leaves were then immersed in sterile distilled water with $0.01 \%$ Tween 20 and conidia were harvested by gently stroking the leaf surface with a small camel's-hair brush. The resulting suspension was filtered through two layers of cheesecloth to remove any debris. The concentration of conidia in the filtrate was determined using a hemocytometer and the counts adjusted to final a concentration of 2 to $3 \times 10^{5}$ conidia/ml using sterile distilled water. The resulting inoculum was dispensed in autoclaved vacuum flasks, cooled to 4 to $5^{\circ} \mathrm{C}$, and transported to the field to inoculate test genotypes.

Maize plants were inoculated at the V2 to V3 stage of growth (Ritchie et al. 1993) as described by Carson (1995). Briefly, every plant in the central row of each plot was inoculated late in the afternoon (i.e., 1500 to $1800 \mathrm{~h}$ ) by placing a 200- $\mu$ l aliquot of inoculum into the leaf whorl using a micropipette. In the first 3 days following inoculation, $200 \mu \mathrm{l}$ of sterile distilled water was added to the whorl of every inoculated plant daily near dusk (i.e., approximately $1830 \mathrm{~h}$ ) to prolong leaf wetness and promote conidia germination and subsequent leaf penetration and infection. Three days after inoculation, six inoculated plants were arbitrarily selected from the central row of each plot and tagged using labels. These tagged plants were used to collect data for the temporal analysis of disease progress, which ensured that the same set of plants was assessed and rated during the epidemic period.

Disease assessment and components of resistance. Nine measures of disease severity and components of resistance were examined; incubation period (IP), latent period (LP), percent diseased leaf area (PDLA), disease severity class, final PDLA (FPDLA), standardized area under the disease progress curve (SAUDPC), weighted mean absolute rate of disease increase, time to transition to the decreasing phase of absolute rate of disease increase, and percent diseased leaf area at the inflection point.

Maize plants were visually inspected starting the third day after inoculation and everyday thereafter, between 1500 and $1800 \mathrm{~h}$, for the formation of water-soaked chlorotic specks indicative of the earliest GLS lesions. IP was subsequently recorded as the number of days from inoculation to appearance of these first lesions (Ward et al. 1999) on $50 \%$ of the total number of plants arbitrarily selected 
in a plot. Exploratory data analyses found IP to be inconsistent among inbred lines across sites and, thus, IP was not evaluated further in subsequent analyses.

From the 10th day after inoculation and every day thereafter, maize plants were visually examined between 1500 and $1800 \mathrm{~h}$ for the formation of the earliest necrotic lesions. LP was subsequently recorded as number of days from inoculation to appearance of the first necrotic lesion on $50 \%$ of the total number of plants arbitrarily selected in a plot (Ringer and Grybauskas 1995).

Beginning 3 to 4 weeks after inoculation and every 5 to 7 days thereafter until the R6 growth stage, the tagged plants were visually assessed and the proportion of necrotic leaf area estimated as

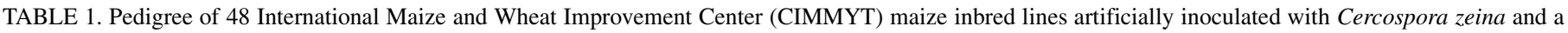
summary of four selected disease resistance components averaged across nine trial environments in western Kenya

\begin{tabular}{|c|c|c|c|c|c|c|c|}
\hline Entry & CML number & Curated pedigree & $\mathrm{CDSG}^{\mathrm{a}}$ & SAUDPC & $\rho^{c}$ & LP (days) ${ }^{\mathrm{d}}$ & Disease reaction $^{\mathrm{e}}$ \\
\hline 1 & 351 & BPVC-163-4-1-1-1TL-1-1TL-B & 1.0 & 29.3 & 0.003 & 21.9 & $\mathrm{R}$ \\
\hline 2 & 204 & 7794-4-1-B*9-1-4-7-4-5-B & 1.0 & 42.8 & 0.022 & 25.6 & $\mathrm{R}$ \\
\hline 3 & 347 & G26SEQ-C3-FS71-1-1-2-1-B & 1.0 & 33.9 & 0.015 & 28.4 & $\mathrm{R}$ \\
\hline 4 & 357 & SA3-C4-FS(6/24)-1-2-2-5-B & 1.0 & 33.2 & 0.002 & 22.8 & $\mathrm{R}$ \\
\hline 5 & 235 & EV8744SR-11-1-1-1-B & 1.0 & 29.9 & 0.002 & 25.0 & $\mathrm{R}$ \\
\hline 6 & 254 & TUXPSEQ-149-2-B*3-\#-\#-1-B & 1.0 & 31.0 & 0.008 & 27.4 & $\mathrm{R}$ \\
\hline 7 & 342 & LAPOSTASEQ-C3-FS1-2-2-3-2-1-B & 1.0 & 37.4 & 0.002 & 22.8 & $\mathrm{R}$ \\
\hline 8 & 160 & P63-C2-FS6-2-1-1-B-2-1-B & 1.2 & 44.5 & 0.005 & 25.8 & $\mathrm{R}$ \\
\hline 9 & 199 & MSR-76-1-B*3-3-3-B & 1.2 & 26.5 & 0.001 & 23.1 & $\mathrm{R}$ \\
\hline 10 & 373 & P43SR-4-1-1-2-1-B-8-1-B & 1.2 & 34.2 & 0.010 & 28.5 & $\mathrm{R}$ \\
\hline 11 & 340 & LAPOSTASEQ-C3-FS20-4-1-1-2-3-B & 1.2 & 40.1 & 0.011 & 24.7 & $\mathrm{R}$ \\
\hline 12 & 387 & $\begin{array}{l}\text { (EV7992/EV8449SR)-C1-F2-334-1OSU8I- } \\
\text { 1-1-B-B-3-B }\end{array}$ & 1.3 & 36.8 & 0.007 & 23.4 & $\mathrm{R}$ \\
\hline 13 & 273 & (AC7643/P43-F7)-2-3-2-1-B & 1.4 & 38.3 & 0.018 & 28.1 & $\mathrm{R}$ \\
\hline 14 & 371 & MBRETW-F2-56-1-1-1-B-B-6-B & 1.4 & 38.6 & 0.021 & 21.4 & $\mathrm{R}$ \\
\hline 15 & 198 & MSR-308-5-B*3-5-1-B & 1.5 & 35.4 & 0.005 & 23.9 & $\mathrm{R}$ \\
\hline 16 & 339 & LAPOSTASEQ-C3-FS297-2-1-1-1-3-B & 1.5 & 48.2 & 0.004 & 26.6 & $\mathrm{R}$ \\
\hline 17 & 210 & $\begin{array}{l}((\mathrm{EV} 8443 / \mathrm{SR}) / \mathrm{EV} 8443 / \mathrm{EV} 8443 / \mathrm{EV} 8443 / \\
\text { EV8443)-39-1-2SR-4-2-2-B }\end{array}$ & 1.7 & 31.6 & 0.005 & 17.0 & $\mathrm{R}$ \\
\hline 18 & 390 & [EV7992]C1F2-430-3-3-3-B-7-B*4 & 1.7 & 38.3 & 0.005 & 23.1 & $\mathrm{R}$ \\
\hline 19 & 206 & $\begin{array}{l}\text { [EV7992\#/EVPO44-SRBC3]\#bF37sr-2-3- } \\
\text { sr-2-4-3-b-b }\end{array}$ & 1.7 & 36.1 & 0.009 & 25.1 & $\mathrm{R}$ \\
\hline 20 & 153 & S8662Q-28-4-B & 1.8 & 41.5 & 0.004 & 23.9 & $\mathrm{R}$ \\
\hline 21 & 363 & BPVC-185-2-1-5-1-5TL-B-6TL-B & 1.8 & 53.4 & 0.018 & 22.6 & $\mathrm{R}$ \\
\hline 22 & 168 & G26QSINT-31-1-2-2-B & 1.8 & 59.7 & 0.011 & 24.6 & $\mathrm{R}$ \\
\hline 23 & 209 & EV7992-\#-B-\#-B-99-1-1-1-6-B & 1.8 & 39.8 & 0.001 & 27.0 & $\mathrm{R}$ \\
\hline 24 & 202 & ZSR923-B*4-5-1-B & 1.8 & 29.8 & 0.002 & 24.4 & $\mathrm{R}$ \\
\hline 25 & 394 & [PL31/POOL16SR//PL9A]C1F2-124-2-B*7 & 2.0 & 59.1 & 0.005 & 23.5 & $\mathrm{R}$ \\
\hline 26 & 213 & $\begin{array}{l}\text { ((EVP30SR/ZS206)/ZS206/ZS206)-\#-B- } \\
\text { 121-2SR-2-2-1-B }\end{array}$ & 2.1 & 53.0 & 0.020 & 23.0 & MR \\
\hline 27 & 391 & [EV7992]C1F2-430-3-3-B-1-B*4 & 2.1 & 49.4 & 0.017 & 23.7 & MR \\
\hline 28 & 312 & S89500-F2-2-2-1-1-B & 2.1 & 44.8 & 0.018 & 21.8 & MR \\
\hline 29 & 205 & EMSR-\#-B-\#-B-F101SR-2-1SR-3-2-4-B & 2.1 & 38.5 & 0.021 & 24.7 & MR \\
\hline 30 & 211 & (EV8449SR/P62)-\#-B-F4SR-1-3SR-4-1-2-B & 2.3 & 71.6 & 0.013 & 22.5 & MR \\
\hline 31 & 103 & P44-C4-FS101-3-\#-1-1-B & 2.3 & 45.3 & 0.001 & 22.8 & MR \\
\hline 32 & 55 & G24TSR-19-3-B & 2.5 & 47.6 & 0.007 & 23.0 & MR \\
\hline 33 & 329 & (SPMAT-C4/EV89MDREY)-165-2-B & 2.7 & 62.2 & 0.005 & 25.8 & MS \\
\hline 34 & 219 & $\begin{array}{c}((\mathrm{EV} 8730 / \mathrm{SR}) / \mathrm{EV} 8730 / \mathrm{EV} 8730 / \mathrm{EV} 8730 / \\
\text { EV8730/EV8730/EV8730)-171-1-1-2-B }\end{array}$ & 2.8 & 59.2 & 0.013 & 18.2 & MS \\
\hline 35 & 72 & ANTGP2-5-\#-1-2-1-1-3-3-1-B & 2.9 & 78.4 & 0.006 & 19.0 & MS \\
\hline 36 & 321 & P502-C0-F1-1-3-1-B & 2.9 & 72.8 & 0.009 & 28.9 & MS \\
\hline 37 & 384 & P502-C1-771-2-2-1-3-B & 3.0 & 66.8 & 0.006 & 23.3 & MS \\
\hline 38 & 220 & $\begin{array}{c}((\mathrm{EV} 8730 / \mathrm{SR}) / \mathrm{EV} 8730 / \mathrm{EV} 8730 / \mathrm{EV} 8730 / \\
\text { EV8730/EV8730/EV8730)-324-1-1-2-B }\end{array}$ & 3.0 & 67.4 & 0.015 & 23.3 & MS \\
\hline 39 & 135 & $\begin{array}{l}\text { (P47-C1-F26-1-\#-B-1/P47-C1-F187-1-\#-B- } \\
\text { 3)-2-4-1-\#-B-30-1-B }\end{array}$ & 3.0 & 58.5 & 0.011 & 24.6 & MS \\
\hline 40 & 183 & G32Q-HS36-3-2-2-1-1-B & 3.1 & 62.2 & 0.007 & 26.0 & MS \\
\hline 41 & 366 & SA8-C2-FS(27/3)-1-3-6-1-B & 3.2 & 55.8 & 0.016 & 24.5 & MS \\
\hline 42 & 197 & MSR-270-2-B*3-5-1-B & 3.2 & 95.3 & 0.016 & 17.4 & MS \\
\hline 43 & 123 & $\begin{array}{l}\text { P47/MPSCWB4-3/PI209135/PI162927// } \\
\text { P1218191/P1209135-4/PI20-9135/ } \\
\text { PI226685//P1317328/PI218191-3/P47/ } \\
\text { MPSWCB4)-9-2-3-B-12-2-8-B }\end{array}$ & 3.2 & 58.9 & 0.013 & 28.6 & MS \\
\hline 44 & 218 & $\begin{array}{c}((\mathrm{EV} 8730 / \mathrm{SR}) / \mathrm{EV} 8730 / \mathrm{EV} 8730 / \mathrm{EV} 8730 / \\
\text { EV8730/EV8730/EV8730)-47-1-1-4-B }\end{array}$ & 3.3 & 91.8 & 0.028 & 25.4 & MS \\
\hline 45 & 184 & G32Q-HS30-2-2-B-1-B & 3.7 & 80.2 & 0.017 & 22.8 & $\mathrm{~S}$ \\
\hline 46 & 102 & P44-C4-FS65-1-\#-2-B-2-B & 3.9 & 66.5 & 0.013 & 18.8 & $\mathrm{~S}$ \\
\hline 47 & 195 & 100MSR & 4.0 & 86.0 & 0.014 & 19.8 & $\mathrm{~S}$ \\
\hline 48 & 190 & G34Q-HS103-1-1-2-B & 5.0 & 97.9 & 0.018 & 11.9 & $\mathrm{~S}$ \\
\hline
\end{tabular}

a Mean gray leaf spot severity grade at the R5 growth stage (CDSG) across all environments, based on a 1-to-5 severity scale (CIMMYT 1985).

b Standardized area under the disease progress curve across all nine trial environments.

c Weighted mean absolute rate of disease increase across all nine trial environments.

d Latent period across all nine trial environments.

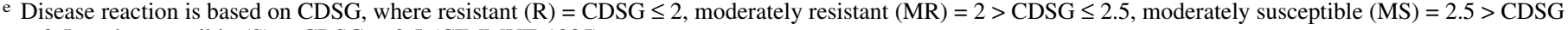
$<3.5$, and susceptible $(\mathrm{S})=\mathrm{CDSG} \geq 3.5$ (CIMMYT 1985). 
PDLA. On each assessment, all leaves on a tagged plant were visually assessed for GLS symptoms, and the mean severity value across all leaves represented the PDLA for a tagged plant. The same rater conducted disease severity assessments in all trial environments. The growth stage of plants at the time of each disease rating was also recorded. At minimum, 12 individual PDLA ratings were taken per tagged plant before leaf senescence. The last PDLA rating for the analysis of temporal progress was recorded at the R5 growth stage because GLS ratings at this stage give the best prediction of yield loss associated with the disease (Paul and Munkvold 2004). In this study, the R5 growth stage corresponded to 83 to 103 days after inoculation across all inbred lines.

At the R5 growth stage, each tagged plant was assigned either a whole-number score or a fraction thereof that was closest to the illustrated CIMMYT (1985) foliar disease scale. This disease scale is based on a 1-to-5 severity class, where $1=$ resistant, $2=$ moderately resistant, $3=$ moderately susceptible, $4=$ susceptible, and $5=$ highly susceptible. The reaction of inbred lines to GLS was finally designated using a CIMMYT disease severity grade (CDSG) as follows: resistant $=\mathrm{CDSG} \leq 2$, moderately resistant $=2>\mathrm{CDSG}$ $\leq 2.5$, moderately susceptible $=2.5>\mathrm{CDSG}<3.5$, and susceptible $=$ CDSG $\geq 3.5$ (CIMMYT 1985).

At the R6 developmental stage, the proportion of diseased leaf area on each tagged plant was visually estimated and recorded as the FPDLA. The R6 developmental stage was selected for assessment of FPDLA because rapid and extensive leaf senescence beyond this stage terminates further expansion of the leaf area that can be infected.

To obtain an overall measure of disease severity over the entire duration of the epidemic, the area under the disease progress curve (AUDPC) was first computed for each tagged plant according to the following equation (Shaner and Finney 1977):

$$
\mathrm{AUDPC}=\sum_{i=1}^{n}\left[\left(y_{i}+y_{i+1}\right) / 2\right]\left(t_{i+1}-t_{i}\right)
$$

where $y_{i}=$ diseased leaf area $(\%)$ estimated on the $i$ th disease assessment date, $t_{i}=$ time (days) from disease onset (i.e., inoculation) to the $i$ th disease assessment date, and $n=$ total number of disease assessments during the epidemic. Because AUDPC values for epidemics with varying durations of disease assessment cannot be compared directly (Simko and Piepho 2012), an SAUDPC was calculated for each tagged plant according to the following equation (Fry 1978):

$$
\mathrm{SAUDPC}=\mathrm{AUDPC} / \mathrm{t}_{\mathrm{n}}
$$

where $t_{n}=$ time (days) from inoculation to the $n$th (i.e., last) disease assessment date.

Individual PDLA ratings were fit to the Von Bertalanffy-Richards growth model (Campbell and Madden 1990) to obtain parameter estimates that characterized the temporal aspects of epidemic progress. The differential form of the Richards model used was expressed as:

$$
d y / d t=\left[r y\left(K^{m^{-1}}-y^{m^{-1}}\right)\right] /\left[(m-1) K^{m^{-1}}\right]
$$

where $r=$ apparent rate of disease increase, $K=$ upper disease asymptote, and $m=$ the shape parameter. The parameter $m$ can take on any real value and when $m=0$ or 2 , equation 3 reduces to a monomolecular or logistic model, respectively, whereas when $m \rightarrow$ 1, equation 3 reduces to a Gompertz model. Mean disease severity data from all tagged plants in each plot were fitted to the model using nonlinear regression implemented in PROC NLIN of SAS with the Marquardt iteration method to generate least squares parameter estimates. Models generated by varying $m$ (i.e., $m=0,1.01$, or 2 ) where evaluated for their fit to disease data and the most appropriate model was selected based on coefficients of determination and plots of residual versus observed data (Campbell and Madden 1990).

Apparent rates of disease increase obtained from disease data fitted to Richards model with dissimilar estimates of $K$ or $m$ cannot be compared directly (Madden et al. 2007). Thus, the weighted mean absolute rate of disease increase parameter (i.e., parameter rho) was calculated for each plot using the following equation (Campbell and Madden 1990):

$$
\rho=r K /(2 m+2)
$$

where $\rho$ is the rho parameter and $K, r$, and $m$ are as defined above.

\begin{tabular}{|c|c|c|c|c|c|c|c|c|}
\hline Year, season, location ${ }^{\mathrm{a}}$ & Longitude & Latitude & Alt (masl) ${ }^{\mathrm{b}}$ & Rainfall (mm) & Day $\left({ }^{\circ} \mathrm{C}\right)^{\mathrm{c}}$ & Night $\left({ }^{\circ} \mathrm{C}\right)^{\mathrm{d}}$ & $\mathrm{RH}(\%)^{\mathrm{e}}$ & Soil type ${ }^{f}$ \\
\hline \multicolumn{9}{|l|}{2012} \\
\hline \multicolumn{9}{|l|}{ Short rains } \\
\hline Kadongo & $34^{\circ} 41^{\prime} 21^{\prime \prime} \mathrm{E}$ & $0^{\circ} 31^{\prime} 28^{\prime \prime} \mathrm{S}$ & 1,421 & 660 & 29.4 & 15.1 & 56 & Nitrosol \\
\hline Kehancha & $34^{\circ} 36^{\prime} 54^{\prime \prime} \mathrm{E}$ & $1^{\circ} 11^{\prime} 38^{\prime \prime} \mathrm{S}$ & 1,471 & 673 & 32.6 & 19.6 & 54 & Ferralsol \\
\hline \multicolumn{9}{|l|}{2013} \\
\hline \multicolumn{9}{|l|}{ Long rains } \\
\hline Kadongo & $34^{\circ} 35^{\prime} 56^{\prime \prime} \mathrm{E}$ & $0^{\circ} 12^{\prime} 08^{\prime \prime} \mathrm{S}$ & 1,442 & 812 & 32.4 & 16.8 & 58 & Dystric nitosols \\
\hline \multicolumn{9}{|l|}{ Short rains } \\
\hline Kadongo & $34^{\circ} 46^{\prime} 04^{\prime \prime} \mathrm{E}$ & $0^{\circ} 41^{\prime} 02^{\prime \prime} \mathrm{S}$ & 1,682 & 963 & 28.2 & 15.1 & 58 & Humic nitosols \\
\hline Kapuonja & $34^{\circ} 35^{\prime} 56^{\prime \prime} \mathrm{E}$ & $0^{\circ} 12^{\prime} 08^{\prime \prime} \mathrm{S}$ & 1,442 & 659 & 30.2 & 16.8 & 59 & Orthic luvisols \\
\hline Kehancha & $34^{\circ} 36^{\prime} 54^{\prime \prime} \mathrm{E}$ & $1^{\circ} 11^{\prime} 38^{\prime \prime} \mathrm{S}$ & 1,471 & 773 & 32.6 & 19.6 & 59 & Ferralsol \\
\hline \multicolumn{9}{|l|}{2014} \\
\hline \multicolumn{9}{|l|}{ Long rains } \\
\hline Kadongo & $34^{\circ} 43^{\prime} 18^{\prime \prime} \mathrm{E}$ & $0^{\circ} 31^{\prime} 28^{\prime \prime} \mathrm{S}$ & 1,421 & 862 & 29.4 & 14.8 & 58 & Nitrosol \\
\hline
\end{tabular}

Least squares estimates of $r, K$, and $m$ for each plot were used to compute the time (days) taken for the transition of absolute rate of

TABLE 2. Characteristics of trial environments used to characterize quantitative resistance to gray leaf spot in maize inbred lines in western Kenya

a Short rain season is from August to November, while the long rain season is from March to July.

b Altitude in meters above sea level.

c Mean day temperature.

d Mean night temperature.

e Relative humidity.

f Soil type designation is based on the FAO classification (FAO 1974). 
disease increase from the increasing- to a decreasing-phase (i.e., duration from inoculation to the disease increase inflection point, $\mathrm{T}_{\mathrm{IP}}$ ) as follows (Madden and Campbell 1990):

$$
\mathrm{T}_{\mathrm{IP}}=[\ln (\beta)-\ln (1-m)](r-1), \text { when } m<1
$$

or

$$
\mathrm{T}_{\mathrm{IP}}=[\ln (\beta)-\ln (m-1)](r-1), \text { when } m<1
$$

where $\beta$ is the constant of integration parameter whose value is $1-y_{0}^{1-m}$ when $m<1$ and $y_{0}^{1-m}-1$ when $m>1$. The parameter $y_{0}$ is the lower disease severity asymptote or the model-predicted estimate of disease severity at epidemic onset, and $m$ is as defined above.

Parameter estimates of the Richards model were also used to compute the PDLA at the inflection point $\left(\mathrm{PDLA}_{\mathrm{IP}}\right)$ as follows (Navas-Cortés et al. 2000):

$$
\mathrm{PDLA}_{\mathrm{IP}}=K m^{1 /(1-\mathrm{m})}
$$

where $K$ and $m$ are defined as above.

Disease resistance component to quantify GLS reaction. To identify the most useful disease resistance component for quantifying the reaction of inbreds to GLS, outputs of the analysis of variance (ANOVA), correlation analysis, and stepwise regression were examined for the following attributes:

(i) Proportion of variation accounted for by the ANOVA model based on the resistance component (i.e., adjusted coefficient of determination $\left[R^{2}\right]$ or coefficient of variation $[\mathrm{CV}]$, extracted from ANOVA results). The statistic $R^{2}$ is interpreted as the proportion of variability in the data explained by the ANOVA model, while CV is a measure of the explained variability in data as a proportion of the mean of the response variable.

(ii) Extent to which disease scores based on the resistance component were consistent across different replications of inbred lines (i.e., CV estimates extracted from ANOVA results).

(iii) Extent to which inbred rankings based on one disease or resistance component were similar to rankings based on other components of disease assessment (i.e., Spearman's rank correlation matrix between a pair of disease resistance components implemented with the SPEARMAN option of PROC CORR of SAS).

(iv) Extent to which the resistance component mirrored the general trend in inbred resistance ratings scored using other disease or resistance components (i.e., Pearson's correlation between the component and other disease components determined from correlation matrix analysis implemented with the default PEARSON option in PROC CORR of SAS).

(v) Ability of the disease or resistance component to reflect individual disease severity ratings recorded throughout the epidemics (i.e., number of individual PDLA ratings required to adequately account for variation of the score, extracted from stepwise regression results).

Critical disease assessment rating for disease screening. To determine individual disease severity ratings that best predicted the most useful disease component, individual severity ratings taken at different times during the epidemic were regressed on this parameter using multiple regression implemented with the STEPWISE selection option in PROC REG of SAS. This option was chosen because it specifies independent variables to be selected for the model based on a stepwise-regression algorithm, which combines a succession of forward-selection and backward-elimination steps. This approach is a modification of the forward-selection method such that variables already in the model can be eliminated if they do not meet the stay criterion (SAS Institute Inc. 2012). Probability limits for entry and stay of individual variables in the regression model were set at $P=0.15$ and $P=0.10$, respectively, to prevent premature gridlocking of the model selection procedure where there was an abundance of variable intercorrelation. A collection of individual disease severity ratings was deemed the best predictor of most useful disease component if they collectively produced a Mallows' $C_{p}$ value that approached the number of parameters in the resultant model (Mallows 1973). The disease severity rating that individually resulted in the largest adjusted partial $R^{2}$ value upon entry into the model was determined as the most critical contributor to the variation in the most useful disease component.

Statistical analyses. Statistical analyses for all disease assessment and resistance component variables, except $\rho$, were based on single-plot data (i.e., either the mean across measurements from the six individual plants in each plot or $50 \%$ of selected plants, as was the case for LP). For the computation of $\rho$, data comprised disease severity values recorded on individual plants in a plot. The effect of inbred lines on FPDLA, LP, PDLA IP, SAUDPC, SAUDPC $_{I P}, \mathrm{~T}_{\mathrm{IP}}$, and $\rho$ were analyzed using the GLIMMIX procedure of SAS. The model fitted to the data were written as $y=\mu+S+E+S \cdot E+B(S, E)+I(S)+I(S \cdot E)+e$, where $y$ is the response variable, $\mu$ is the overall mean, $S$ is the set, $E$ is the environment, $B$ is the block or replication, $I$ is inbred line, and $e$ is the experimental error. Here, both $I$ and $S$ were treated as fixed effects, while $E$ and its corresponding interactions were treated as random effects. The residual pseudo-likelihood (RSPL) option in GLIMMIX was used to generate estimates of $R^{2}$ that behave like coefficients of determination in linear models as described by Piepho (2019). Outputs from GLIMMIX were first postprocessed to obtain estimates of total variance, variance due to effects added in the full model relative to the null model, and variance associated with adjusted mean. These outputs were then submitted to the \%CD_GLMM macro (Piepho 2019) to compute estimates of $R^{2}$. The effects of inbred lines on CDSG were analyzed using nonparametric techniques (Shah and Madden 2004). Here, PROC RANK was used to generate midranks of the disease ratings, while PROC MIXED with the ANOVAF option was used to obtain ANOVA-type test statistics. The LD_CI macro was then implemented to estimate relative effects, their standard errors, and confidence intervals. Correlation between pairs of disease assessment and resistance component variables and regression analyses were conducted using standard approaches as described above. All statistical analyses described above were implemented in SAS (version 9.3; SAS Institute, Cary, NC, U.S.A.).

\section{RESULTS}

Weather and disease epidemics across trial environments. Rainfall amounts and ambient temperatures at trial locations varied during the growing seasons from 2012 to 2014 (Table 2). The highest rainfall amounts were recorded at Kadongo during the short rain season in 2013, while the lowest rainfall amounts were recorded at Kapuonja during the short rain season in 2012. In general, rainfall amounts were considerably lower in 2012 compared with 2013 or 2014. Mean day temperatures at the experimental sites ranged from $28.2^{\circ} \mathrm{C}$ during the short rain season at Kadongo in 2013 to $32.7^{\circ} \mathrm{C}$ during the long rain season at Kehancha in 2013. Unlike rainfall and temperature levels, relative humidity levels were generally similar across the trial environments (Table 2).

Observable disease symptoms developed on all 48 maize inbred lines inoculated at all of the trial environments in 2013 and 2014. However, no GLS symptoms were observed by the R4 growth stage on 23 to $29 \%$ of the inbred lines following inoculation across the three trial sites in 2012. In addition, disease severity levels on the remaining inbred lines in 2012 were very low across sites despite inoculation of test genotypes. Thus, only data collected on 
the inbred lines in the nine trial environments in 2013 and 2014 are reported in this study. Of the nine trial environments where GLS developed on all inbred lines, the highest disease severity levels were observed at Kadongo during the long rain season in 2013 and 2014, where the most susceptible inbred line (CML 190) had a mean disease severity value of 5 (based on a scale of 1 to 5) across the nine trial environments (Table 1). In contrast, the lowest disease severity level was observed at Kehancha during the short rain season in 2013, where the mean disease severity on the most resistant inbred lines (CML 204, 235, 254, 342, 347, 351, and 357) across all trial environments was 1.0 (based on a scale of 1 to 5). Across all inbred lines, mean disease severity was lowest at Kehancha during the long rain season in 2013 (mean severity $=2.98$ ) and highest at Kadongo during the long rain season in 2014 (mean severity $=3.63$ ) (Fig. 1).

Distribution of disease severity and components of resistance. Frequency distribution of different measures of disease severity and components of resistance at these nine trial environments were fairly continuous, unimodal, and normally distributed (Table 3). For example, FPDLA was normally distributed in all environments except at Kehancha during the short rain season in 2013 (Table 3). Similarly, SAUDPC and the weighted mean absolute rate of disease increase, $\rho$, were normally distributed in all trial environments except at Kehancha during the short rain season in 2013 and at Kapuonja during the long rains in 2013 (Table 3). The remaining measures of disease severity $\left(\right.$ CDSG, PDLA ${ }_{I P}$ and SAUDPC $_{I P}$ ) were normally
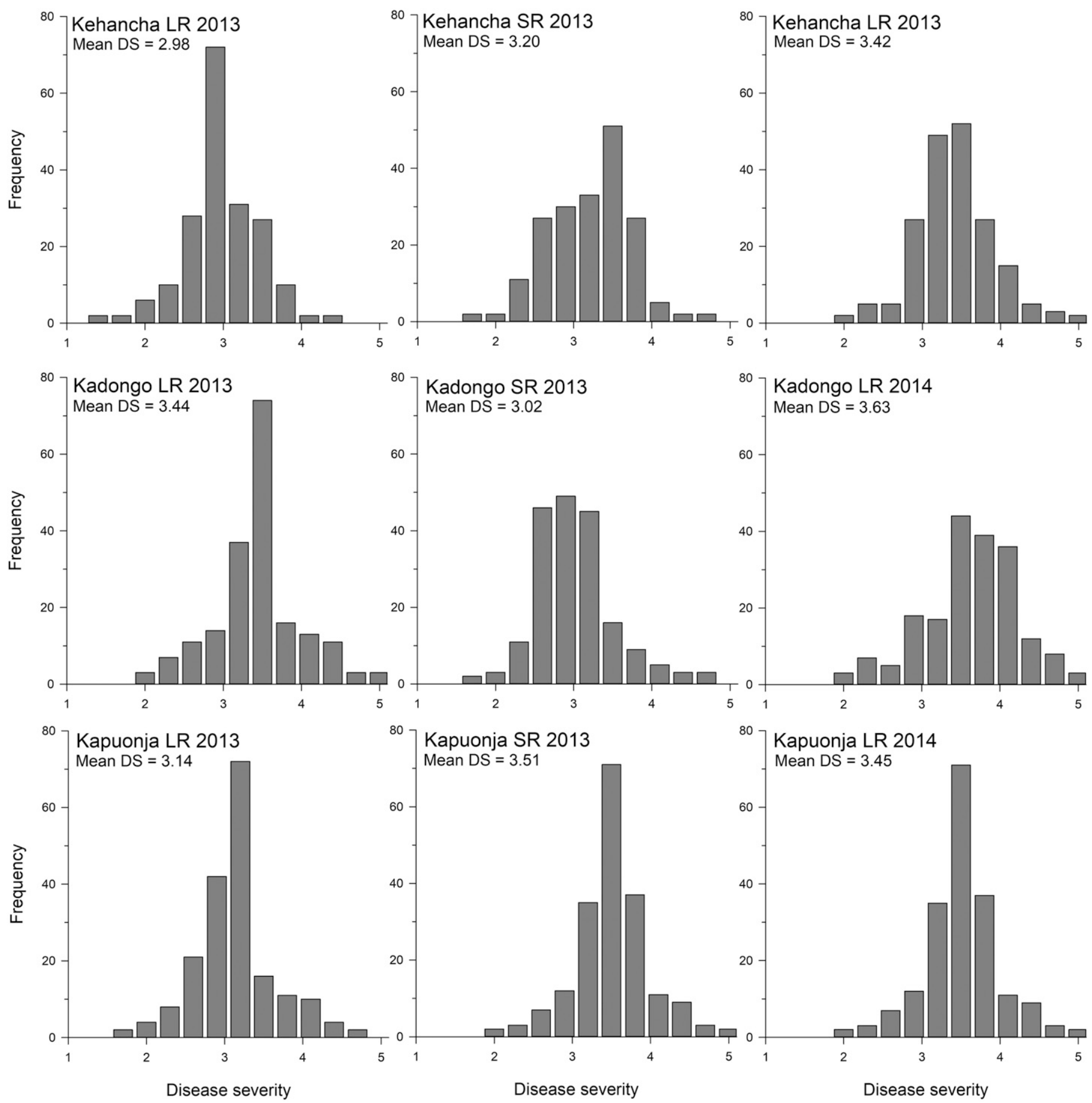

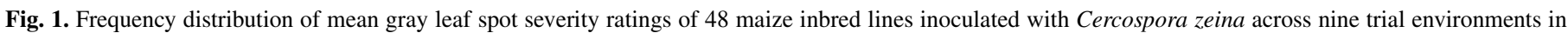

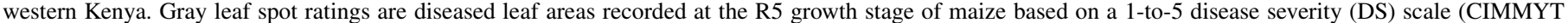
1985). $\mathrm{LR}=$ long rain season and $\mathrm{SR}=$ short rain season. 
distributed in five to six of the nine trial environments (Table 3). The only exceptions to this trend were LP and $\mathrm{T}_{\mathrm{IP}}$ that were not normally distributed in most of the trial environments based on the ShapiroWilk test statistics (Table 3).

Reaction of inbred lines to gray leaf spot. Inbred lines exhibited a wide range of disease reaction across the nine trial environments during the study period (Table 1). Approximately $52 \%$ of the entries were classified as resistant and $8 \%$ of the inbred lines were designated as susceptible, with the rest of the inbred lines (40\%) being either moderately resistant or moderately susceptible to GLS (Table 1). Some of the resistant inbred lines included CML $204,235,254,342,347,351$, and 357, all of which had a CDSG $=1$, while CML 102, 184, 190, and 195, designated as susceptible, had a CDSG > 3.5. In general, resistant inbred lines had relatively lower SAUDPC and CDSG values and smaller estimates of $\rho$ than susceptible inbred lines (Table 1). For example, the mean SAUDPC for resistant and susceptible inbred lines was 38.8 and 82.7, respectively. The CDSG for resistant and susceptible lines also followed a similar trend, with values of 1.3 and 4.2 , respectively. Similarly, the mean $\rho$ for resistant and susceptible inbred lines was 0.008 and 0.016 , respectively (Table 1 ).

Disease variable for quantifying resistance of inbred lines. The most useful disease assessment or resistance component variable for quantifying the resistance of inbred lines to GLS was determined based on an examination of the results from ANOVA and correlation analyses. All disease assessment and resistance component variables except $\rho$ were significantly $(P<0.05)$ affected by inbred lines (Table 4 ). However, of all the variables that were significantly affected by inbred lines, SAUDPC accounted for the highest proportion $\left(R^{2}=89.4\right)$ while LP accounted for the lowest proportion $\left(R^{2}=48.6\right)$ of variation in the full ANOVA model. In addition, the estimate for the $C V$ was largest for LP but comparatively lower for SAUDPC or the other remaining disease assessment or resistance components. Thus, SAUDPC was considered more consistent in quantifying GLS resistance among inbred lines than the remaining disease assessment or resistance components. Disease assessment and resistance components were significantly $(P<0.05)$ affected by the environment as well as inbred-environment interaction (Table 4$)$.

Measures of disease severity and components of resistance were all significantly $(P<0.01)$ correlated (Table 5$)$, with the strength and direction of Spearman correlation varying among variables. The strongest correlation $(r=0.81)$ was observed between $\mathrm{T}_{\mathrm{IP}}$ and SAUDPC $_{\mathrm{IP}}$, whereas the weakest $(r=-0.11)$ association was observed between LP and $\rho$. Furthermore, SAUDPC was strongly positively correlated with FPDLA, $\rho$, and CDSG $(0.48<r<0.68)$ but negatively correlated with $\mathrm{T}_{\mathrm{IP}}(|r|=0.49)$. Similarly, SAUDPC $\mathrm{IP}_{\mathrm{IP}}$ was positively correlated with LP and $\mathrm{T}_{\mathrm{IP}}(0.39<r<0.82)$ but negatively correlated with FPDLA, $\rho$, and CDSG $(0.39<|r|<0.48)$. In all instances except where the correlation was between a pair of disease assessment variables that were scored at nearly the same time (e.g., CDSG and FPDLA), absolute values of the coefficients of correlation between SAUDPC and other every disease assessment or resistance component were numerically larger than corresponding correlations with any other variable (Table 5). For example, SAUDPC $_{I P}$ was more strongly correlated with $T_{I P}$ than with any other disease assessment or resistance component. Rankings of inbred lines based on Pearson's correlation also followed a trend similar to that of the Spearman correlation analysis but with slightly weaker associations among disease variables (data not shown).

In general, the time of disease rating during plant development influenced the correlation between individual severity ratings and disease assessment or resistance component variables (i.e., FPDLA, SAUDPC, $\rho$, and so on) (Fig. 2). For example, disease severity ratings recorded earlier during plant growth (e.g., at V3 to V18) were less correlated with disease assessment or resistance component variables than ratings recorded toward the end of the season (e.g., at VT to R4). The only exception to this trend was with $\mathrm{LP}$ and $\mathrm{T}_{\mathrm{IP}}$, where the correlation coefficients between disease ratings with these two variables was low and did not increase with crop maturity (Fig. 2).

Critical disease assessment ratings for screening inbred lines. Disease severity ratings recorded at 76 to 82 days after inoculation (i.e., DS-R4) corresponding to the R4 growth stage explained the largest proportion $\left(R^{2}=72.4 \%\right)$ of the variation in SAUDPC (Table 6). Inclusion of disease severity ratings recorded at 68 to 75 days after inoculation (i.e., DS-R3) further improved the explained variation in SAUDPC to $84.9 \%$. However, supplementary inclusion of disease severity ratings recorded at VT and R1 growth stages explained the greatest variation in SAUDPC $\left(R^{2}=93.9 \%\right)$. Based on the Mallow's $C_{p}$ statistics, the model that best explained the variation in SAUDPC consisted of disease severity ratings recorded at R1, R3, R4, and VT $(P=0.0409)$. This model had a $C_{p}$ value of 4.7 , a value that was close to the total number of model parameters (including the intercept) of 5 (Table 6). Disease severity ratings at R3 and R4 had the largest adjusted partial $R^{2}$ values and, thus, were considered to be the most critical in the variation in SAUDPC.

\section{DISCUSSION}

Host genetic resistance is considered the most economically important strategy in the management of GLS in maize. Thus, characterization of host resistance continues to be a key element in breeding programs that aim to improve hybrid resistance. The

TABLE 3. Shapiro-Wilk statistics for test of normality of gray leaf spot resistance components and other disease attributes for 48 maize inbred lines inoculated with Cercospora zeina in nine trial environments in western Kenya

\begin{tabular}{|c|c|c|c|c|c|c|c|c|}
\hline \multirow[b]{2}{*}{ Environment $^{\mathrm{a}}$} & \multicolumn{8}{|c|}{ Disease assessment variable ${ }^{b}$} \\
\hline & LP & FPDLA & SAUDPC & $\rho$ & CDSG & $\mathrm{PDLA}_{\mathrm{IP}}$ & SAUDPC $_{\text {IP }}$ & $\mathrm{T}_{\mathrm{IP}}$ \\
\hline Kehancha LR 2013 & $0.867 * *$ & $0.966 \mathrm{~ns}$ & $0.978 \mathrm{~ns}$ & $0.942 \mathrm{~ns}$ & $0.967 * *$ & $0.983 \mathrm{~ns}$ & $0.977 \mathrm{~ns}$ & $0.971 * *$ \\
\hline Kehancha SR 2013 & $0.755 * *$ & $0.951 *$ & $0.961 *$ & $0.914 *$ & $0.955 * *$ & $0.873 * *$ & $0.872 * *$ & $0.981 \mathrm{~ns}$ \\
\hline Kehancha LR 2014 & $0.678 * *$ & $0.981 \mathrm{~ns}$ & $0.968 \mathrm{~ns}$ & $0.934 \mathrm{~ns}$ & $0.971 \mathrm{~ns}$ & $0.985 \mathrm{~ns}$ & $0.988 \mathrm{~ns}$ & $0.967 * *$ \\
\hline Kadongo LR 2013 & $0.861 * *$ & $0.926 \mathrm{~ns}$ & $0.982 \mathrm{~ns}$ & $0.982 \mathrm{~ns}$ & $0.968 \mathrm{~ns}$ & $0.971 \mathrm{~ns}$ & $0.979 \mathrm{~ns}$ & $0.977 * *$ \\
\hline Kadongo SR 2013 & $0.572 * *$ & $0.956 \mathrm{~ns}$ & $0.977 \mathrm{~ns}$ & $0.965 \mathrm{~ns}$ & $0.973 \mathrm{~ns}$ & $0.972 * *$ & $0.974 \mathrm{~ns}$ & $0.951 * *$ \\
\hline Kadongo LR 2014 & $0.982 \mathrm{~ns}$ & $0.968 \mathrm{~ns}$ & $0.988 \mathrm{~ns}$ & $0.934 \mathrm{~ns}$ & $0.982 \mathrm{~ns}$ & $0.985 \mathrm{~ns}$ & $0.977 \mathrm{~ns}$ & $0.971 * *$ \\
\hline Kapuonja LR 2013 & $0.850 * *$ & $0.948 \mathrm{~ns}$ & $0.954 * *$ & $0.944 * *$ & $0.950 * *$ & $0.975 * *$ & $0.965 * *$ & $0.947 * *$ \\
\hline Kapuonja SR 2013 & $0.881 \mathrm{~ns}$ & $0.969 \mathrm{~ns}$ & $0.979 \mathrm{~ns}$ & $0.879 \mathrm{~ns}$ & $0.980 \mathrm{~ns}$ & $0.987 \mathrm{~ns}$ & $0.968 * *$ & $0.940 * *$ \\
\hline Kapuonja LR 2014 & $0.855^{* *}$ & $0.962 \mathrm{~ns}$ & $0.956 \mathrm{~ns}$ & $0.927 \mathrm{~ns}$ & $0.954 * *$ & $0.970 * *$ & $0.985 \mathrm{~ns}$ & $0.955 * *$ \\
\hline
\end{tabular}

${ }^{\text {a }} \mathrm{LR}=$ long rain season (March to July) and $\mathrm{SR}=$ short rain season (August to November).

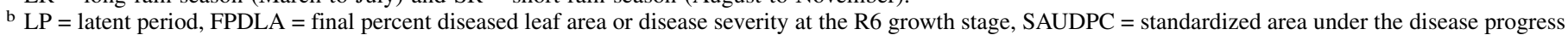
curve, $\rho=$ weighted mean absolute rate of disease increase, $C D S G=$ disease severity scored using a scale at the R5 growth stage, $P D L A_{I P}=$ percent diseased leaf area at the inflection point or transition of absolute rate of disease increase from the increasing to the decreasing phase, $\mathrm{SAUDPC}_{\mathrm{IP}}=\mathrm{SAUDPC}_{\mathrm{S}}$ the inflection point, and $\mathrm{T}_{\mathrm{IP}}=$ time taken to reach the inflection point or duration from inoculation to the transition of disease increase from the increasing to the decreasing phase. Statistics followed by asterisks $*$ and $* *$ are significant at $P=0.05$ and 0.01 , respectively, while ns $=$ nonsignificant. 
identification of epidemiologically important attributes of the disease can further facilitate identification of useful maize genotypes for use in plant breeding programs. In this study, partial resistance to GLS was characterized in 48 elite maize inbred lines under field conditions in western Kenya based on specific variables of disease assessment and components of resistance. A number of inbred lines were found to be resistant to GLS across nine trial environments, with disease resistance being expressed primarily as low SAUDPC and $\rho$ values. Furthermore, SAUDPC was identified as the most useful variable for quantifying partial resistance in inbred lines, and individual disease ratings at the R4 stage of plant growth were nearly as effective as SAUDPC in ranking inbred lines for resistance to GLS. Resistant inbred lines identified in this study could be used as parental lines in the development of maize hybrids that are resistant to GLS in eastern Africa.

In this study, mean GLS severity varied across all trial environments, with very limited to no disease being observed on most of the inbred lines in 2012, whereas high levels of disease were observed on inbred lines at the trial environments in 2013 and 2014. The differences in disease severity reported here may be due to differences in environmental conditions across time and sites that influenced disease development. Warm temperatures (i.e., 24 to $29^{\circ} \mathrm{C}$ ) and high relative humidity favor the development of GLS and epidemics progress faster when environmental conditions are conducive for the reproduction of the pathogen (de Nazareno et al. 1993). Although temperatures were generally similar in 2012 to 2014 and conducive for GLS, the rainfall amounts were considerably lower in 2012 than in 2013 and 2014. This low level of precipitation may explain why GLS was not observed on most inbred lines in 2012. In addition, a combination of high rainfall amounts and conducive temperatures $\left(29.4^{\circ} \mathrm{C}\right)$ may also explain the high levels of GLS severity reported at Kadongo during the short rain and long rain seasons in 2013 and 2014, respectively.

Partial resistance to GLS in inbred lines was generally expressed as smaller SAUDPC, CDSG, and $\rho$ values. This observation is consistent with reports in studies that attributed resistance to several minor genes in other pathosystems (Ojiambo et al. 2000; SandovalIslas et al. 2007). Among the resistant inbred lines, CML 199, 210, $235,347,351$, and 357 had the lowest SAUDPC, CDSG, and $\rho$ values across the nine trial environments. These inbred lines could be used as parental lines in developing hybrids that are resistant to GLS within the region. Although these resistant inbred lines have not yet been used to develop commercial hybrids, some of them have manifested excellent prospects for breeding and precommercial hybrid maize production. For example, results from previous genetic polymorphism studies found CML 357 to be a good candidate for population improvement (Kanagarasu et al. 2012). Similarly, CML 199 has been used to develop genotypes whose combination with other inbred lines outperformed some commercial hybrids (Kamutando et al. 2018). Inbred lines CML 190 and CML 195 were the most susceptible across trial environments. These specific resistant and susceptible inbred lines could serve as standard

TABLE 4. Analysis of variance of gray leaf spot severity and components of resistance of six sets of 48 maize inbred lines inoculated with Cercospora zeina in nine trial environments in western Kenya

\begin{tabular}{|c|c|c|c|c|c|c|c|c|c|}
\hline \multirow[b]{2}{*}{ Variation $^{\mathrm{a}}$} & \multirow[b]{2}{*}{$\mathrm{df}^{\mathrm{b}}$} & \multicolumn{8}{|c|}{ Disease severity or component of resistance ${ }^{c}$} \\
\hline & & LP & FPDLA & SAUDPC & $\rho$ & CDSG & PDLA $_{\text {IP }}$ & SAUDPC $_{I P}$ & $\mathrm{~T}_{\text {IP }}$ \\
\hline $\mathrm{S}$ & 5 & $86.4 *$ & $7,826.6^{*}$ & $63,562.9^{*}$ & $2.482 \mathrm{~ns}$ & $1.246^{*}$ & $7,866.5^{*}$ & $51,784.3^{*}$ & $3.72 *$ \\
\hline B (S, E) & 108 & $312.5^{*}$ & $1,543.0^{*}$ & $1,065.0^{*}$ & $0.115^{*}$ & $1.342 *$ & $323.2 *$ & $814.7^{*}$ & $1.54 \mathrm{~ns}$ \\
\hline I (S) & 42 & $73.0^{*}$ & $3,567.0^{*}$ & $4,433.0^{*}$ & $0.190 \mathrm{~ns}$ & $0.510^{*}$ & $386.4 *$ & $2,451.2 *$ & $2.44 *$ \\
\hline $\mathrm{I}(\mathrm{S} \times \mathrm{E})$ & 336 & $39.1 \mathrm{~ns}$ & $656.3 *$ & $421.8^{*}$ & $0.009 \mathrm{~ns}$ & $0.164 *$ & $116.8^{*}$ & $341.8 *$ & $0.62 *$ \\
\hline $\mathrm{CV}(\%)^{\mathrm{e}}$ & $\ldots$ & 30.3 & 15.8 & 22.2 & 14.2 & 17.1 & 15.8 & 21.4 & 24.2 \\
\hline
\end{tabular}

a Source of variation: $\mathrm{S}=$ set, $\mathrm{E}=$ environment, $\mathrm{B}=$ block, and $\mathrm{I}=$ inbred line. Both $\mathrm{I}$ and $\mathrm{S}$ were treated as fixed effects, while $\mathrm{E}$ and its corresponding interactions were treated as random effects.

b Degrees of freedom.

${ }^{c} \mathrm{LP}=$ latent period, FPDLA = final percent diseased leaf area or disease severity at the R6 growth stage, SAUDPC $=$ standardized area under the disease progress curve, $\rho=$ weighted mean absolute rate of disease increase, $\mathrm{CDSG}=$ disease severity scored using a scale at midphysiological maturity at R5 growth stage, PDLA $_{I P}=$ percent diseased leaf area at the inflection point or transition of absolute rate of disease increase from the increasing to the decreasing phase, $\mathrm{SAUDPC}_{\mathrm{IP}}=\mathrm{SAUDPC}$ at the inflection point, and $\mathrm{T}_{\mathrm{IP}}=$ time (days) from inoculation to the transition of disease increase from the increasing to the decreasing phase. Values presented are mean sum of squares; values followed by an asterisk $\left(^{*}\right)$ are significant at $P=0.01$, while those followed by ns are nonsignificant at $P=0.05$.

d Coefficients of determination that behave like coefficients of determination in linear models and computed using the residual pseudo-likelihood option in GLIMMIX

e Coefficient of variation.

TABLE 5. Spearman rank correlation among disease severity and resistance components used to quantify the reaction of 48 maize inbred lines to gray leaf spot caused by Cercospora zeina across nine trial environments in western Kenya

\begin{tabular}{|c|c|c|c|c|c|c|c|}
\hline \multirow[b]{2}{*}{ Variable } & \multicolumn{7}{|c|}{ Disease assessment/resistance component variable ${ }^{a}$} \\
\hline & LP & FPDLA & SAUDPC & $\rho$ & CDSG & SAUDPC $_{I P}$ & $\mathrm{~T}_{\mathrm{IP}}$ \\
\hline LP & $\ldots$ & $-0.30 *$ & $-0.19^{*}$ & $-0.11 *$ & $-0.28 *$ & $0.39 *$ & $0.50 *$ \\
\hline FPDLA & $\ldots$ & $\ldots$ & $0.48^{*}$ & $0.58^{*}$ & $0.68 *$ & $-0.47 *$ & $-0.57 *$ \\
\hline$\rho$ & $\ldots$ & $\ldots$ & $\ldots$ & $\ldots$ & $0.52 *$ & $-0.40^{*}$ & $-0.51 *$ \\
\hline CDSG & $\ldots$ & $\ldots$ & $\ldots$ & $\ldots$ & $\ldots$ & $-0.47 *$ & $-0.40 *$ \\
\hline SAUDPC $_{I P}$ & $\ldots$ & $\ldots$ & $\ldots$ & $\ldots$ & $\ldots$ & $\ldots$ & $0.81 *$ \\
\hline
\end{tabular}


checks in field evaluation of new genotypes for resistance to GLS in Kenya.

Frequency distribution of different measures of disease severity or resistance components has been used to infer the expression of partial resistance in host genotypes, with a continuous distribution being indicative of partial resistance (Cañizares and Forbes 1995; Ojiambo et al. 2000). In this study, frequency distribution of most of the examined variables for disease assessment and resistance components was continuous and normal, suggesting that these disease variables may be conditioned by polygenic loci expressed in a quantitative manner. This assertion is further supported by the significant inbredxenvironment interaction observed in this study, where inbred disease severity differed across environments. In general, SAUDPC explained a high degree of variation within the disease severity dataset compared with other disease variables, indicating that this disease measure was less subject to stochastic effects of experimental error and more consistent across inbred lines. Although the same observation could potentially be made for $\mathrm{T}_{\mathrm{IP}}$, that inference should be interpreted with caution because $\mathrm{T}_{\mathrm{IP}}$ is a regression-predicted approximation and is not based on original observations. The generally weak but significant negative correlation of SAUDPC with LP suggests that disease reaction in resistant inbred lines could partly be explained by delayed onset of the secondary infection cycles associated with late sporulation from primary lesions. Similarly, the significant negative though weak correlation between SAUDPC and $\rho$ suggests that lesion multiplication or expansion rate throughout the epidemic was, on average, slower among resistant than susceptible inbred lines. This inference is consistent with the findings of Gordon et al. (2006), who reported that quantitative resistance to GLS was characterized by fewer and shorter lesions. As demonstrated by Lyimo et al. (2013), fewer and shorter lesions can arise from reduced postpenetration establishment of $C$. zeina germlings or decreased growth of hyphal wefts within mesophyll tissue. Alternatively, they could arise from reduced secondary conidiation and subsequent autoinfection, as reported by Ringer and Grybauskas (1995). However, infection events prior to penetration are unlikely to have influenced SAUDPC and $\rho$ because no differences in conidia germination, germ tube growth, or appressoria formation have been detected between resistant and susceptible maize (Lyimo et al. 2013; Ringer and Grybauskas 1995). Similarly, differential sensitivity of leaf tissue to the toxin cercosporin is unlikely to have been the basis for the observed trends in SAUDPC and $\rho$ in this study because, unlike C. zeae-maydis, C. zeina does not produce the phytoxin (Swart et al. 2017). Previous tests for association of genotype reactions with cercosporin production or penetration of stomata by germinated hyphae have also been inconclusive (Gwinn et al. 1987).

The more conspicuous dissimilarity in inbred rankings based on disease ratings recorded before the VT growth stage and disease ratings taken beyond 70 days after inoculation appear to contradict the significant correlations among GLS ratings across different stages of maize growth previously reported by Saghai Maroof et al. (1993). However, our observation is consistent with the declining agreement between early and late GLS ratings with increased intervals between ratings as previously reported by Bubeck et al. (1993). The apparent discordance between early and late disease ratings might be explained partly by the higher density of functional stomata in adult relative to juvenile leaves (Miranda et al. 1981),

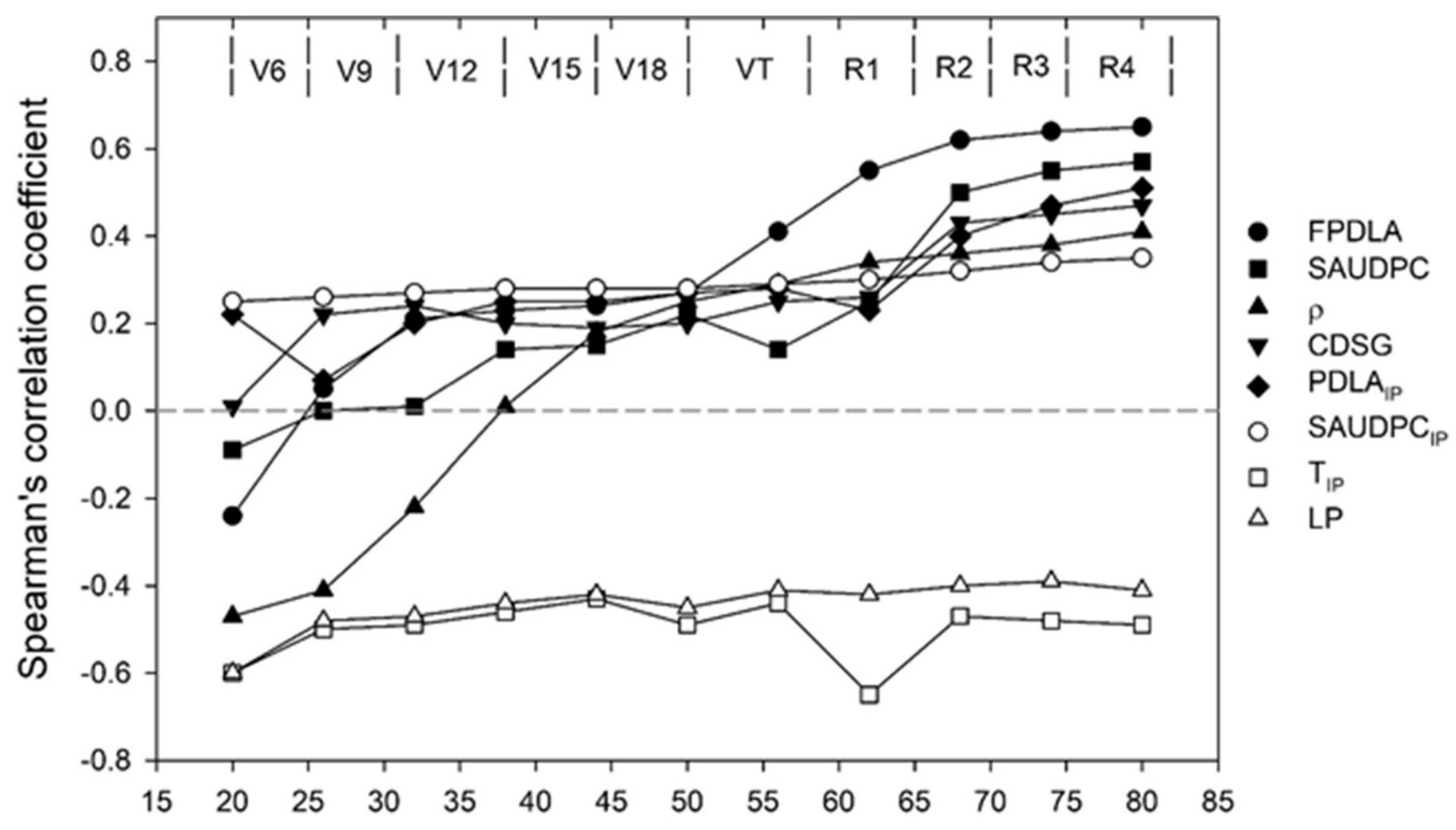

Days after inoculation

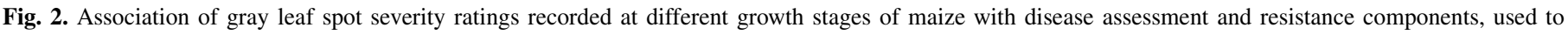

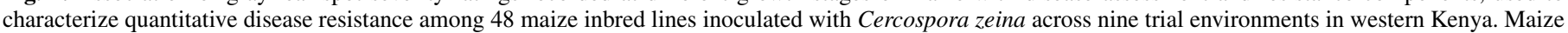

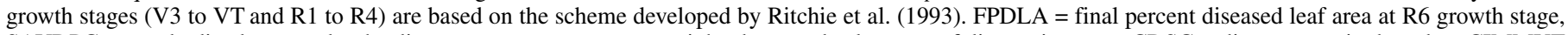

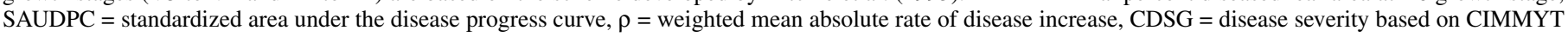

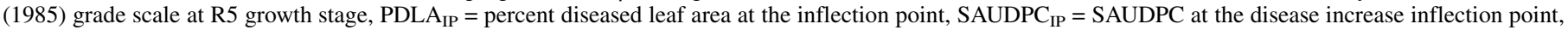
$\mathrm{T}_{\mathrm{IP}}=$ time (in days) from inoculation to disease increase inflection point, and $\mathrm{LP}=$ latent period. 
given that stomata play a crucial role in the penetration of maize leaf by the GLS fungus (Kim et al. 2011). Stomata are also essential for emergence of pathogen conidiophores that ultimately give rise to secondary conidia (Caldwell and Laing 2005). Thus, a denser concentration of stomata in older leaves possibly facilitates more intense penetration and conidiation from primary lesions, thereby intensifying disease severity on older plants. This inference is further supported by the reported association of variations in stomata penetration with the differential response of three maize cultivars to GLS infection (Gwinn et al. 1987) and reports of positive correlations between secondary conidiation and stomata density in the maize-GLS pathosystem (de Nazareno et al. 1992).

The choice of a disease assessment variable or resistance component to quantify disease reaction of test genotypes is critical in the identification and selection of resistant germplasm. In this study, SAUDPC explained the greatest proportion of the variation attributed to the ANOVA model, ranked inbred reaction most consistently across replications, closely mirrored inbred scores obtained with the other infection assessment components, yielded inbred rankings similar to those produced by the other rating components, and assimilated infection assessments throughout the epidemics. Thus, SAUDPC was determined to be the most useful disease assessment variable for quantifying resistance of inbred lines to GLS. The strong correlation of SAUDPC with $T_{I P}$ demonstrates that the former component properly captured the timing of disease acceleration. In addition, the pronounced contribution of late GLS ratings to the variation in SAUDPC suggests that the latter adequately reflected the impact of lesion growth, ancillary conidiation, and autoinfection cycles on the ultimate disease severity. Thus, SAUDPC reduces the risk of inadvertent rating of susceptible entries as resistant because of disease escape or late lesion expansion. The significant correlation of SAUDPC with late disease assessment ratings suggests that the latter were nearly as effective as SAUDPC in ranking resistance of inbred lines. However, the significant increase in proportion of SAUDPC variation explained by individual disease ratings taken at the R1 growth stage suggests that effective screening for resistance is possible before the R5 stage of plant growth. Thus, reliable resistance scores can be obtained at approximately the R1 growth stage and fungicides applied thereafter to permit use of preliminary evaluation nurseries for seed production.

Considerable time and effort is often invested in recording multiple disease measurements needed to compute SAUDPC. This challenge can be partly mitigated by using mathematical procedures similar to those proposed by Jeger and Viljanen-Rollinson (2001). Basically, these mathematical procedures require just two sufficiently spaced data points to generate reasonably reliable estimates of AUDPC values if the applicable disease progress curves have the classical sigmoid shapes. However, AUDPC values estimated in this manner are merely crude approximations that may not represent the true level of epidemic development. An alternative solution is the use of disease ratings or disease scores measured with descriptive disease scales (Del Ponte et al. 2017) such as the CIMMYT (1985) or Ward (1996) schemes. The strong correlation of SAUDPC with FPDLA and CDSG observed in this study suggests that this approach might be effective in prebreeding and preliminary evaluation trials that involve large base populations. However, nearly all such one-time scores are not suitable for assessing components of the infection cycle that need prioritization when breeding for partial resistance (Parlevliet 1979). Additionally, breeding for reduced rates of disease increase based on one-time disease ratings is often less effective for polycyclic than monocyclic diseases (Leonard and Mundt 1984).

Disease severity at different stages of plant development can influence the degree to which GLS impacts crop performance and yield development in maize (Paul and Munkvold 2004). Thus, identification and use of disease assessment periods when disease has the most impact on yield is key to quantifying disease reaction of host genotypes. In this study, disease assessments recorded at R1, R3, R4, and VT growth stages of maize best predicted SAUDPC. This suggests that disease assessments recorded in the late growth stages of maize are a good predictor of inbred reaction to GLS. In addition, the integration of multiple disease severity assessments over the duration of the epidemic was necessary to obtain the most efficient disease variable to quantify disease resistance. Disease severity ratings recorded at the $\mathrm{R} 4$ growth stage individually explained the greatest proportion of the overall variation in SAUDPC. This observation is consistent with previous findings that a single GLS rating taken near physiological maturity or just before leaf senescence is nearly as effective as composite measures such as SAUDPC in studying the genetic basis of quantitative resistance to GLS (Elwinger et al. 1990; Thompson et al. 1987). A molecular mapping by study Gordon et al. (2004) also found that the maximum percent leaf area affected by GLS colocalizes to the same quantitative trait locus (QTL) as AUDPC. Thus, loci controlling these two characteristics might be genetically linked, thereby making single disease severity assessments recorded around peak epidemic severity to be just as effective as multiple assessments spread over a longer duration in quantifying the reaction of genotypes to GLS.

In this study, the IP of $C$. zeina was found to be inconsistent among inbred lines, indicating that it may not be useful in characterizing partial resistance to GLS in maize. Similar results were also reported by Gordon et al. (2006), where the IP of C. zeaemaydis was found to have a lower heritability and, thus, a less useful measure of GLS resistance. A molecular mapping study by Gordon et al. (2006) found that only one of two QTLs associated with reduced GLS severity colocalized with the QTL for prolonged IP. Furthermore, IP was also strongly influenced by variations in the environment, thereby suggesting that genotypic effects were only of modest importance in its expression. In another study, Ringer and Grybauskas (1995) reported that, although IP was longer on

TABLE 6. Summary of stepwise regression of standardized area under the disease progress curve (SAUDPC)-based estimation of gray leaf spot severity on individual diseased leaf area ratings recorded at different intervals during the assessment of 48 maize inbred lines across nine trial environments in western Kenya

\begin{tabular}{|c|c|c|c|c|c|c|c|c|}
\hline \multirow[b]{2}{*}{ Step } & \multicolumn{2}{|c|}{ Variable $^{\mathrm{a}}$} & \multirow[b]{2}{*}{$N^{\mathrm{b}}$} & \multicolumn{5}{|c|}{ Variable selection statistics ${ }^{\mathrm{c}}$} \\
\hline & Entered & Removed & & Partial $R^{2}$ & Model $R^{2}$ & Mallows $C_{p}$ & $F$ value & $P$ value \\
\hline 1 & DS-R4 & $\ldots$ & 1 & 0.7243 & 0.724 & 182.0 & 823.51 & 0.0001 \\
\hline 2 & DS-R3 & $\ldots$ & 2 & 0.1215 & 0.849 & 56.7 & 86.02 & 0.0209 \\
\hline 4 & DS-R1 & $\ldots$ & 4 & 0.0271 & 0.939 & 4.7 & 8.65 & 0.0409 \\
\hline 5 & $\ldots$ & DS-VT & 3 & 0.0270 & 0.912 & 4.9 & 2.85 & 0.0801 \\
\hline 6 & DS-V12 & $\ldots$ & 4 & 0.0269 & 0.938 & 4.6 & 2.55 & 0.1482 \\
\hline
\end{tabular}

a DS-V12, DS-VT, DS-R1, DS-R3, and DS-R4 refer to disease severity ratings recorded at different growth stages of maize and correspond to 32 to 38,50 to 58,58 to 64,68 to 75 , and 76 to 82 days after inoculation, respectively.

b Number of variables in model.

c Mallows (1973) $C_{p}$ statistic assesses model suitability when comparing models with different input variables. 
moderately resistant relative to susceptible hybrids, it only translated into large and significant differences in overall GLS severity or mean absolute rates of disease increase if environmental conditions remained favorable for disease development. As indicated by Leonard and Mundt (1984), disease-suppressive environments tend to reduce the number of infection cycles per season, making IP or the closely related LP relatively less important than other components of the infection cycle in driving the overall rate of epidemic development. The weak and, in some cases, nonsignificant correlations between LP and other measures of infection severity suggest that LP might represent a form of resistance to GLS not adequately captured by the other measures of infection. However, the extremely high CVs associated with the LP indicate that this component of disease resistance is strongly influenced by perturbations (i.e., "noise") in the physical components of the environment. Therefore, more consistent ranking of resistance to GLS based on LP would perhaps require evaluations to be conducted under greenhouse or growth chamber conditions to facilitate adequate control of physical components of the environment such as temperature, moisture, and soil characteristics.

\section{ACKNOWLEDGMENTS}

We thank A. Diallo, G. Srivanasan, and K. Pixley at the International Center for Maize and Wheat Improvement (CIMMYT) in Mexico for providing germplasm that was used in this study.

\section{LITERATURE CITED}

Asea, G. 2001. Reaction of maize genotypes in young stages to Cercospora zeae-maydis and influence of infested maize residue on progress and spread of gray leaf spot in central Uganda. M.Sc. thesis, Makerere University, Kampala, Uganda.

Asea, G., Lipps, P., Pratt, R., Gordon, S., and Adipala, E. 2005. Development of greenhouse inoculation procedures for evaluation of partial resistance to Cercospora zeae-maydis in maize inbreds. J. Phytopathol. 153: 647-653.

Ayers, J. E., Johnson, M. W., and Hill, R. R. 1985. Identifying resistance to gray leaf spot. Pages 157-175 in: Proc. 39th Maize Sorghum Res. Conf. American Seed Trade Association, Washington DC.

Bair, W., and Ayers, J. E. 1986. Variability in isolates of Cercospora zeaemaydis. Phytopathology 76:129-132.

Balestre, M., Von Pinho, R. G., and Brito, A. H. 2012. Bayesian inference to study genetic control of resistance to gray leaf spot in maize. Genet. Mol. Res. 11:17-29.

Benson, J. M., Poland, J. A., Benson, B. M., Stromberg, E. L., and Nelson, R. J. 2015. Resistance to gray leaf spot of maize: Genetic architecture and mechanisms elucidated through nested association mapping and nearisogenic line analysis. PLoS Genet. 11:e1005045.

Berger, D. K., Carstens, M., Korsman, J. N., Middleton, F., Kloppers, F. J., Tongoona, P., and Myburg, A. A. 2014. Mapping QTL conferring resistance in maize to gray leaf spot disease caused by Cercospora zeina. BMC Genet. 15:60.

Bubeck, D. M., Goodman, M. M., Beavis, W. D., and Grant, D. 1993. Quantitative trait loci controlling resistance to gray leaf spot in maize. Crop Sci. 33:838-847.

Caldwell, P. M., and Laing, M. D. 2005. Light, scanning and transmission electron microscopy studies on the conidiogenesis of Cercospora zeaemaydis on maize. S. Afr. J. Plant Soil 22:207-213.

Campbell, C. L., and Madden, L. V. 1990. Introduction to Plant Disease Epidemiology. John Wiley \& Sons, New York, NY, U.S.A.

Cañizares, C. A., and Forbes, G. A. 1995. Foliage resistance to Phytophthora infestans (Mont.) de Bary in the Ecuadorian national collection of Solanum phureja ssp. phureja Juz \& Buk. Potato Res. 38:3-10.

Carson, M. L. 1995. Inheritance of latent period length in maize infected with Exserohilum turcicum. Plant Dis. 79:581-585.

CIMMYT. 1985. Managing Trials and Reporting for CIMMYT's International Maize Testing Program. Lisboa 27, D.F., Mexico.

Coates, S. T., and White, D. G. 1998. Inheritance of resistance to gray leaf spot in crosses involving selected resistant inbred lines of maize. Phytopathology 88:972-982.

Crous, P. W., Groenewald, J. Z., Groenewald, M., Caldwell, P., Braun, U., and Harrington, T. C. 2006. Species of Cercospora associated with grey leaf spot of maize. Stud. Mycol. 55:189-197.
Danson, J., Lagat, M., Kimani, M., and Kuria, A. 2008. Quantitative trait loci QTLs for resistance to grey leaf spot and common rust diseases of maize. Afr. Biotechnol. 7:3247-3254.

Del Ponte, E. M., Pethybridge, S. J., Bock, C. H., Michereff, S. J., Machado, F. J., and Spolti, P. 2017. Standard area diagrams for aiding severity estimation: Scientometrics, pathosystems, and methodological trends in the last 25 years. Phytopathology 107:1161-1174.

de Nazareno, N. R. X., Lipps, P. E., and Madden, L. V. 1992. Survival of Cercospora zeae-maydis in corn residue in Ohio. Plant Dis. 76:560-564.

de Nazareno, N. R. X., Madden, L. V., and Lipps, P. E. 1993. Characterization of gray leaf spot epidemics of maize. J. Plant Dis. Prot. 100:410-425.

Diallo, A. O., Kikafunda, J., Wolde, L., Odongo, O., Mduruma, Z. O., Chivatsi, W. S., Friesen, D. K., Mugo, S., and Bänziger, M. 2001. Drought and low nitrogen tolerant hybrids for the moist mid-altitude ecology of eastern Africa. Pages 206-212 in: Integrated Approaches to Higher Maize Productivity in the New Millennium: Proc. Seventh Eastern and Southern Africa Regional Maize Conf. D. K. Friesen and A. F. E. Palmer, eds. Nairobi, Kenya, 5-11 February 2001

Elwinger, G. F., Johnson, M. W., Hill, R. R., Jr., and Ayers, J. E. 1990. Inheritance of resistance to gray leaf spot of maize. Crop Sci. 30:350-358.

FAO. 1974. Soil Map of the World. Food and Agriculture Organization of the United Nations and UNESCO, Paris, France.

Freppon, J. T., Pratt, R. C., and Lipps, P. E. 1996. Chlorotic lesion response of maize to Cercospora zeae-maydis and its effect on gray leaf spot disease. Phytopathology 86:733-738.

Fry, W. E. 1978. Quantification of general resistance of potato cultivars and fungicide effects for integrated control of potato late blight. Phytopathology 68:1650-1655.

Geiger, H. G., and Heun, M. 1989. Genetics of quantitative resistance to fungal diseases. Annu. Rev. Phytopathol. 27:317-341.

Gevers, H. O., and Lake, J. K. 1994. GLS1-A major gene for resistance to grey leaf spot in maize. S. Afr. J. Sci. 90:377-379.

Goodwin, S. B., Dunkle, L. D., and Zisman, V. L. 2001. Phylogenetic analysis of Cercospora and Mycosphaerella based on the internal transcribed spacer region of ribosomal DNA. Phytopathology 91:648-658.

Gordon, S. G., Bartsch, M., Matthies, I., Gevers, H. O., Lipps, P. E., and Pratt, R. C. 2004. Linkage of molecular markers to Cercospora zeae-maydis resistance in maize. Crop Sci. 44:628-636.

Gordon, S. G., Lipps, P. E., and Pratt, R. C. 2006. Heritability and components of resistance to Cercospora zeae-maydis derived from maize inbred VO613Y. Phytopathology 96:593-598.

Gwinn, K. D., Steizig, D. A., and Brooks, J. L. 1987. Effects of corn plant age and cultivar on resistance to Cercospora zeae-maydis and sensitivity to cercosporin. Plant Dis. 71:603-606.

Jeger, M. J., and Viljanen-Rollinson, S. L. H. 2001. The use of the area under the disease-progress curve (AUDPC) to assess quantitative disease resistance in crop cultivars. Theor. Appl. Genet. 102:32-40.

Kamutando, C. N., Magorokosho, C., and Dari, S. 2018. Combining ability for grain yield performance among CIMMYT germplasm adapted to the midaltitude conditions. J. Agric. Sci. 10:253-264.

Kanagarasu, S., Nallathambi, G., Ganesan, K. N., Kannan, S., Shobhana, V. G., and Senthil, N. 2012. Determination of genetic polymorphism among indigenous and exotic maize inbreds using microsatellite markers. Afr. J. Biotechnol. 12:5723-5728.

Kim, H., Ridenour, J. B., Dunkle, L. D., and Bluhm, B. H. 2011. Regulation of stomatal tropism and infection by light in Cercospora zeae-maydis: Evidence for coordinated host/pathogen responses to photoperiod? PLoS Pathog 7:e1002113.

Kinyua, Z. M., Smith, J. J., Kibata, G. N., Simons, S. A., and Langat, B. C. 2010. Status of grey leaf spot disease in Kenyan maize production ecosystems. Afr. Crop Sci. J. 18:183-194.

Kuki, M. C., Scapim, C. A., Rossi, E. S., Mangolin, C. A., do Amaral Júnior, A. T., and Pinto, R. J. B. 2018. Genome wide association study for gray leaf spot resistance in tropical maize core. PLoS One 13:e0199539.

Leonard, K. J., and Mundt, C. C. 1984. Methods for estimating epidemiological effects of quantitative resistance to plant diseases. Theor. Appl. Genet. 67:219-230.

Lipps, P. E. 1995. Gray leaf spot of corn. Pages 37-44 in: Proc. 7th Annu. Integrated Crop Manage. Conf. Iowa State University, Ames, IA, U.S.A.

Lyimo, H. J. F., Pratt, R. C., and Mnyuku, R. S. O. W. 2013. Infection process in resistant and susceptible maize (Zea mays L.) genotypes to Cercospora zeae-maydis (type II). Plant Prot. Sci. 49:11-18.

Madden, L. V., and Campbell, C. L. 1990. Nonlinear disease progress curves. Pages 181-229 in: Epidemics of Plant Diseases, Mathematical Analysis, and Modeling, 2nd ed. Ecological Studies 13. J. Kranz, ed. Springer-Verlag, Berlin, Germany.

Madden, L. V., Hughes, G., and van den Bosch, F. 2007. The Study of Plant Disease Epidemics. American Phytopathological Society, St. Paul, MN, U.S.A. 
Makumbi, D., Betran, F. J., Bänziger, M., and Ribaut, J. M. 2011. Combining ability, heterosis and genetic diversity in tropical maize (Zea mays L.) under stress and non-stress conditions. Euphytica 180:143162.

Mallows, C. L. 1973. Some comments on $C_{p}$. Technometrics 15:611-675.

Meisel, B., Korsman, J., Kloppers, F. J., and Berger, D. K. 2009. Cercospora zeina is the causal agent of grey leaf spot disease of maize in southern Africa. Eur. J. Plant Pathol. 124:577-583.

Menkir, A., and Ayodele, M. 2005. Genetic analysis of resistance to gray leaf spot in midaltitude maize inbred lines. Crop Sci. 45:163-170.

Miranda, V., Baker, N. R., and Long, S. P. 1981. Anatomical variation along the length of the Zea mays leaf in relation to photosynthesis. New Phytol. 88:595-605.

Navas-Cortés, J. A., Hau, B., and Jiménez-Díaz, R. M. 2000. Yield loss in chickpeas in relation to development of Fusarium wilt epidemics. Phytopathology 90:1269-1278.

Ojiambo, P. S., Nyanapah, J. O., Lung'aho, C., Karinga, J. K., and Kidanemariam, H. M. 2000. Comparing different epidemiological models in field evaluations of selected genotypes from Solanum tuberosum CIP population A for resistance to Phytophthora infestans (Mont.) De Bary in Kenya. Euphytica 111:211-219.

Parlevliet, J. 1979. Components of resistance that reduce the rate of epidemic development. Annu. Rev. Phytopathol. 17:203-222.

Paul, P. A., and Munkvold, G. P. 2004. A model-based approach to preplanting risk assessment for gray leaf spot in maize. Phytopathology 94 : 1350-1357.

Paul, P. A., and Munkvold, G. P. 2005. Influence of temperature and relative humidity on sporulation of Cercospora zeae-maydis and expansion of gray leaf spot lesions on maize leaves. Plant Dis. 89:624-630.

Piepho, H. P. 2019. A coefficient of determination $\left(R^{2}\right)$ for generalized linear mixed models. Biometrical J. 61:860-872.

Ringer, C. E., and Grybauskas, A. P. 1995. Infection cycle components and disease progress of gray leaf spot on field maize. Plant Dis. 79:24-28.

Ritchie, S. W., Hanway, J. J., Benson, G. O., and Herman, J. C. 1993. How a corn plant develops. In: Iowa State University Science and Technical Cooperative and Extension Service Report No. 48. J. C. Herman, ed. Iowa State University, Ames, IA, U.S.A.

Rufty, C. R., and Main, C. E. 1989. Components of partial resistance to blue mold in six tobacco genotypes under controlled environmental conditions. Phytopathology 79:606-609.

Saghai Maroof, M. A., van Scoyoc, S. W., Yu, Y. G., and Stromberg, E. L. 1993. Gray leaf spot disease of maize: Rating methodology and inbred line evaluation. Plant Dis. 77:583-587.

Sandoval-Islas, J. S., Broers, L. H. M., Mora-Aguilera, G., Parlevliet, J. E., Osada-Kawasoe, S., and Vivar, H. E. 2007. Quantitative resistance and its components in 16 barley cultivars to yellow rust, Puccinia striiformis $\mathrm{f}$. $\mathrm{sp}$. hordei. Euphytica 153:295-308

SAS Institute Inc. 2011. SAS/STAT 9.3 User's Guide. SAS Institute Inc., Cary, NC, U.S.A.

SAS Institute Inc. 2012. SAS/OR 9.3 User's Guide: Mathematical Programming Examples. SAS Institute Inc., Cary, NC, U.S.A

Schnable Lab. 2014. Controlled pollination of maize. Iowa State University, Ames, IA, U.S.A. https://schnablelab.plantgenomics.iastate.edu/resources/ pollination/

Seebold, K. W., Kucharek, T. A., Datnoff, L. E., Correa-Victoria, F. J., and Marchetti, M. A. 2001. The influence of silicon on components of resistance to blast in susceptible, partially resistant, and resistant cultivars of rice. Phytopathology 91:63-69.

Shah, D. A., and Madden, L. V. 2004. Nonparamteric analysis of ordinal data in designed factorial experiments. Phytopathology 94:33-43.

Shaner, G., and Finney, R. E. 1977. The effect of nitrogen fertilization on the expression of slow-mildewing resistance in Knox wheat. Phytopathology 67:1051-1056.

Sibiya, J., Tongoona, P., Derera, J., and Rij, V. N. 2012. Genetic analysis and genotype $\mathrm{x}$ environment $(\mathrm{G} \times \mathrm{E})$ for grey leaf spot disease resistance in elite African maize (Zea mays L.) germplasm. Euphytica 185: 349-362.

Simko, I., and Piepho, H. P. 2012. The area under the disease progress stairs: Calculation, advantage, and application. Phytopathology 102:381-389.

Stromberg, E. L. 1986. Gray leaf spot disease of maize. Virginia Co-operative Extension Service Publication 450-072. Virginia Polytechnic Institute and State University, Blacksburg, VA, U.S.A

Swart, V., Crampton, B. G., Ridenour, J. B., Bluhm, B. H., Olivier, N. A., Meyer, J. J. M., and Berger, D. K. 2017. Complementation of CTB7 in the maize pathogen Cercospora zeina overcomes the lack of in vitro cercosporin production. Mol. Plant-Microbe Interact. 30:710-724.

Thompson, D. L., Berquist, R. R., Payne, G. A., Bowman, D. T., and Goodman, M. M. 1987. Inheritance of resistance to gray leaf spot in maize. Crop Sci. 27:243-246.

Vasal, S. K., Srinivasan, G., Cordova, H., Pandey, S., Jeffers, D., Bergvinson, D., and Beck, D. 1999. Inbred line evaluation nurseries and their role in maize breeding at CIMMYT. Maydica 44:341-351.

Vasal, S. K., Srinivasan, G. F., González, C., Beck, D. L., and Crossa, J. 1993. Heterosis and combining ability of CIMMYT's quality protein maize germplasm: II. Subtropical. Crop Sci. 33:51-57.

Ward, J. M. J. 1996. Epidemiology and management of gray leaf spot: A new disease of maize in South Africa. Ph.D. thesis, University of Natal, Pietermaritzburg 3200, South Africa.

Ward, J. M. J., Stromberg, E. L., Nowell, D. C., and Nutter, F. W., Jr. 1999. Gray leaf spot: A disease of global importance. Plant Dis. 83:884-895. 